
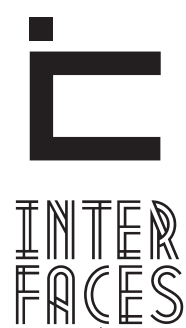

CIENTÍFICAS

EDUCAÇÃO

\title{
PROGRAMA HORA DE ESTUDO: A FORMAÇ̃̃O CONTINUADA COMO CONQUISTA E OS DESAFIOS DA ADESÃO
}

Tereza Cristina Cerqueira da Graça ${ }^{1}$

\section{RESUMO}

A partir de documentos institucionais e depoimentos, 0 artigo descreve o percurso histórico do Programa Hora de Estudo; uma parte destacada da política de formação continuada dos professores da rede municipal de ensino de Aracaju. Instituído nos anos noventa pela Secretaria da Educação, em atendimento as reivindicações do magistério, o programa passou por diversas modificações, visando o engajamento dos professores numa formação voltada para a melhoria da qualidade do ensino. A partir da bibliografia corrente analisa a ausência da maioria dos professores, concluindo que o absenteísmo docente se deve à descontinuidade administrativa, às instabilidades da relação poder público-sindicato e a pouca disposição dos professores em investir na sua própria formação por esta via.

\section{PALAVRAS-CHAVE}

Professores. Formação continuada. Municipal Schools. Aracaju.

\section{ABSTRACT}

From institutional documents and interviews, the article describes the historical background of the Time to Study Program, a detached part of the policy of continuous training of teachers of municipal schools of Aracaju. Established in the nineties by the Department of Education, in response to demands of teaching, the program has undergone several changes in order to engage teachers in training aimed at improving the quality of education. From the current literature examines the absence of most teachers, concluding that teacher absenteeism is due to administrative discontinuity, the relative instability of government-union and teachers' unwillingness to invest in their own training in this way.

\section{KEYWORDS}

Teachers. Continuous Training. Municipal Schools. Aracaju. 


\section{RESUMEN}

Con base en los documentos institucionales y entrevistas, el artículo describe los antecedentes históricos del programa de estudios de tiempo, como siendo una parte separada de la política de formación continuada de los profesores de las escuelas públicas de Aracaju, sometidas al ayuntamiento. Fundada en los años noventa por el Departamento de Educación, en respuesta a las demandas de la enseñanza, el programa ha sufrido varios cambios con el fin de involucrar a los docentes la formación destinada a enriquecer la calidad de la educación. Según la literatura actual, se puede examinar la ausencia de la mayoría de los pro- fesores, concluyendo que, los episodios de absentismo por parte de los docentes son debido a la discontinuidad administrativa relativa a inestabilidad entre gobierno y sindicato, además de la falta de interés del profesorado a la hora invertir en su propia formación en este sentido.

\section{PALABRAS CLAVE}

Maestros. La Educación Continuada. Escuelas Municipales. Aracaju.

\section{INTRODUÇÃO}

A formação continuada dos professores tem sido um desafio histórico em nosso País. Desde final do século XIX, faz-se presente nas produções teórico-pedagógicas dos intelectuais que refletiram sobre o panorama educacional brasileiro; nas primeiras décadas do século XX, os Pioneiros da Educação Nova reclamavam a necessidade de investir na formação inicial e continuada dos professores como requisito imprescindível à expansão e melhoria do ensino.

Na década de cinquenta, o professor Nunes Mendonça lastimava a situação precária dos professores sergipanos; seja pela falta de formação, seja pela baixa qualidade da formação inicial. O "Simpósio sobre os Problemas Aracajuanos", promovido pelo candidato e depois prefeito de Aracaju, José Conrado de Araújo (19591963), do qual participaram reconhecidos profissionais da educação sergipana, também conclamou o investimento na formação dos professores da rede municipal.

O início de uma política de formação mais sistematizada na Rede de Municipal de Ensino de Aracaju data dos anos sessenta, quando algumas professoras primárias fizeram um curso de supervisão promovido pela Cades - Campanha de Aperfeiçoamento e Difusão do Ensino Secundário, na cidade de Recife-PE. Elas ganharam diploma de licenciatura curta em supervisão escolar e deram início ao acompanhamento sistemático do trabalho docente nas escolas. Nas décadas de 70 e 80, a Secretaria de Educação realizou grandes encontros de planejamento anual e estabeleceu coordenadores pedagógicos para as pequenas escolas da rede.

A Lei de Diretrizes e Bases da Educação Nacional - LDBEN 9.394/96 destaca o papel da formação em serviço e delega aos sistemas de ensino a responsabilidade pela valorização dos profissionais da educação através do aperfeiçoamento profissional continuado (artigos 61 a 67). Desde então, a formação docente adquiriu valor estratégico nas reformas educacionais. Em 2003, o Ministério da Educação instituiu a Rede Nacional de Formação Continuada de Professores da Educação Básica, um programa que se estende por todo o País, com oferta de cursos nas diversas áreas, em parceria com universidades e centros de pesquisa. 
Dentro das ações de formação continuada da Secretaria Municipal de Educação - Semed - se destaca o Programa Hora de Estudo, que começou na década de 1990 e se estende até os dias de hoje. Ao longo da sua existência, esse programa passou por inúmeras transformações, objetivando sobreviver à resistência da maioria dos professores e firmar-se enquanto lócus de aprimoramento do saber-fazer docente.

A partir de documentos produzidos pela Semed, depoimentos e outros registros, bem como da biblio-

\section{A FORMACÃO CONTINUADA ATRAVÉS DA "HORA DE ESTUDO: DA REIVINDICAÇÃO À ES- TRUTURAÇ̃̃O DE UM PROGRAMA"}

Garcia define política de formação continuada como um conjunto de atividades desenvolvidas pelos professores em exercício, realizadas em grupos ou individualmente, objetivando o desenvolvimento pessoal e profissional, "na direção de prepará-los para a realização de suas atuais tarefas ou outras novas". (GARCIA, 1995, p. 27).

Nessa perspectiva, o tema do direito à formação continuada figurou na pauta sindical no final da década de 1980, quando os professores conquistaram a redução da jornada de trabalho em sala de aula de trinta para vinte horas, acrescidas de cinco horas semanais para estudos e planejamentos coletivos.

A principal tese defendida por uma parcela da liderança sindical era a melhoria da qualidade do ensino pela ampliação do tempo "extraclasse" do professor. Contratado para uma jornada de 40 horas semanais, o mestre teria 20 horas em sala de aula e um expediente ( 5 horas) para se reunir com seus pares para estudar, trocar ideias e experiências e planejar conjuntamente seu trabalho pedagógico, já que o tempo grafia sobre o tema, este artigo descreve o percurso histórico do programa, analisando suas reconfigurações, ao longo da última década, na perspectiva de obter a adesão da maioria dos professores e influir na melhoria do processo ensino-aprendizagem. Nessa perspectiva, aponta as descontinuidades administrativas, as instabilidades na relação entre a gestão pública e a organização sindical e a pouca disposição da categoria docente em investir na sua própria formação através da frequência a este programa.

individual (horas de 'coordenação') estava garantido nas 15 horas livres.

À Secretaria da Educação caberia providenciar as condições para que os professores pudessem empregar as cinco horas em eventos de formação continuada, com encontros, cursos, palestras, seminários, etc. Desse modo, em 1988, o magistério municipal conquistou o que ainda é um sonho para boa parte da categoria docente da educação básica brasileira. (Lei 1.350/88, art. 71).

Entretanto, para outra parcela das lideranças sindicais, a conquista foi tão somente salarial, pois, não obtendo o reajuste pleiteado, a redução de tempo em sala de aula incidiria diretamente numa melhor remuneração total, inclusive com possibilidades de ampliação dos ganhos individuais através de outra ocupação, já que agora todos teriam apenas um turno de trabalho na rede. Aliás, foi este o discurso que mais aplacou os ímpetos dos grevistas mais aguerridos; que ninguém ficasse receoso: a Secretaria não teria capacidade de organizar o aproveitamento dessas 
'horas de estudo' para todos os mais de mil e setecentos professores.

Contrariando a certeza de muitos, em 1991, a Secretaria da Educação estruturou o que chamou de "Programa Horas de Estudo - PHE", alugando um imóvel, adaptando-o para acolher os professores e estabelecendo um calendário de encontros e temáticas, sob a coordenação da Diretoria de Ensino. Os grupos foram formados a partir das áreas/disciplinas de atuação, com destaque para os professores que atuavam na primeira fase do Ensino Fundamental; para esses, os encontros priorizaram o tema da alfabetização e do letramento.

Assim, essa gestão (1989-1992) teve o mérito de ter iniciado e mantido os encontros de 'Hora de Estudo', inclusive contratando consultores e mobilizando seus técnicos e professores para a elaboração da "Proposta Curricular Elaborada Coletivamente para a Rede de Ensino Público e Gratuito de Aracaju: elementos de uma trajetória”. 0 documento, lançado no último dia útil de dezembro de 1992, infelizmente, acabou sendo engavetado pelas administrações seguintes.

\section{1ạ REESTRUTURAÇ̃̃O DO PHE: PRÉDIO PRÓ- PRIO, CULTURA, ARTE E PUBLICACÕES}

Em outubro de 1995, foi inaugurado o Centro Municipal de Aperfeiçoamento de Recursos Humanos "Professor Fernando Lins de Carvalho". Prédio de dois pavimentos, com quatro salas de aula, pátio interno, cozinha e auditório, além dos espaços reservados à administração. Localizado próximo a algumas das maiores e prestigiadas escolas da rede, à sede do sindicato e em um bairro (Siqueira Campos) onde fluem quase todas as linhas de ônibus da capital e de algumas cidades fronteiriças.

Entretanto, os grupos de estudos estavam desmobilizados e o PHE não aconteceu, sendo o espaço utilizado para reuniões, seminários e cursos determinados pelos projetos da Semed ou programas federais. Ademais, a administração municipal havia tomado medidas 'moralizadoras' e de contenção financeira implantando ponto eletrônico e reduzindo a carga horária de muitos professores que acumulavam empregos públicos; além disso, havia se manifestado contra o processo de eleição para diretores das escolas, uma conquista da categoria implantada desde 1986; o que deixava as lideranças sindicais ariscas e o conjunto dos professores pouco receptivo às políticas de formação continuada da Secretaria.

De 1997 a 2000, uma nova gestão administrativa assume a Prefeitura de Aracaju recebendo, logo nos primeiros meses, a decisão do Supremo Tribunal Federal que determinava a inconstitucionalidade das eleições para diretores de escolas; o pleito do prefeito anterior chegava em boa hora!

A maioria dos diretores eleitos concluiu seus mandatos, embora alguns poucos tenham sido exonerados. $\mathrm{O}$ ano seguinte trouxe de volta a nomeação dos diretores por indicação política e a instituição, por força da nova Lei de Diretrizes e Bases da Educação Nacional - LDB 9.394/96, do Sistema Municipal de Educação com a reestruturação administrativa e pedagógica da Secretaria da Educação. Essa gestão estimulou a produção acadêmica dos professores e a divulgação das experiências exitosas da rede de ensino com a criação da Revista Hora de Estudo, uma publicação que se pretendia quadrimestral, mas que ao cabo de quatro anos, conseguiu publicar apenas cinco edições.

Desse modo, o PHE fora homenageado com a revista, embora não tenha sido reestruturado com agen- 
da e programação definidas. O Cemarh ganhou uma biblioteca especificamente destinada aos professores e continuou sendo um espaço de encontros e eventos da rede.

Nas eleições de 2000, o grupo no poder acabou por apoiar o candidato a prefeito que obtinha a simpatia e adesão de importantes lideranças sindicais, contribuindo decisivamente para a vitória do Partido dos Trabalhadores que iniciou sua gestão com a promessa de fazer valer a maior bandeira do magistério: o retorno das eleições para diretores escolares.

Nessa nova gestão, além dos eventos corriqueiros, o Cemarh se tornou um espaço de fazeres artístico-culturais voltados ao desenvolvimento de projetos socioeducativos e pedagógicos das escolas, promovendo oficinas de pintura, teatro, música, artesanato, modelagem, reciclagem de materiais, capoeira, etc. para alunos e professores.

Somente a partir de 2003, uma nova gestão da Semed começou a reestruturar o PHE, ocasião em que apenas um grupo de professores continuava atuando de modo organizado e frequente - o pessoal do Ensino Religioso. Mobilizar novamente a categoria docente para a frequência ao programa exigiria muita capacidade de convencimento e mobilização. Afinal, a Semed se encontrava em seu terceiro gestor, experimentando a paralisia e os percalços que a descontinuidade administrativa provoca.

Uma das medidas foi reunir alguns profissionais que ministravam as oficinas de arte e cultura popular num projeto intitulado 'Laborarte' que funcionou no Cemarh, atendendo às escolas circunvizinhas no contraturno, ampliando a jornada dos estudantes das séries finais do Ensino Fundamental. Assim, não daria cabo ao trabalho da gestão anterior, descontentando os professores de Arte, um dos poucos grupos que ainda conseguia articular-se e produzir.

O Encontro Cultural e Pedagógico que ocorreu na gestão anterior foi repaginado, ganhando um tom mais acadêmico; o evento priorizaria as experiências pedagógicas exitosas das escolas, que seriam apresentadas pelos próprios professores, de modo a valorizar o estudo, o empenho e a criatividade, elevando a autoestima e revelando talentos.

O III Encontro Pedagógico e Cultural reuniu cerca de trezentos educadores e contou com 40 projetos pedagógicos em dois dias de exposições; algumas delas mediadas por recursos tecnológicos surpreendentes para a ocasião. 0 mesmo ocorreu nos dois encontros seguintes, de modo que alguns professores foram convidados a participar de eventos em outros estados.

É importante registrar que esses encontros resultaram em publicações denominadas "Anais dos Encontros Pedagógicos”, que reúne os projetos apresentados com registro fotográfico e nota biográfica do(s) professor(es) proponente(s). Uma equipe qualificada selecionava os projetos, orientava a melhoria dos textos, organizava o evento, que contava com stands de exposição dos materiais produzidos pelas escolas, e responsabilizava-se pela uniformização dos textos na formatação dos Anais. Em 2010, a Semed fechou a publicação de cinco Anais (2004, 2005, 2007, 2008 e 2009). Ainda há apresentações culturais dos alunos, algumas delas como parte de projetos selecionados.

As equipes pedagógicas da Semed estavam animadas; algumas áreas já contavam com grupos de estudo que frequentavam de modo mais sistemático o Cemarh. Entretanto, uma crise administrativa interrompeu parcialmente os trabalhos de retomada total do Programa Hora de Estudo. 


\section{2ª REESTRUTURAÇÃO: AUTONOMIA E ESTÍ- MULO À PRODUÇÃO}

Em 2005, com o prefeito reeleito e uma nova gestão na Semed, a mobilização interna para a reestruturação do Programa Hora de Estudo recomeça. A ideia agora é que os educadores lotados nas escolas, notadamente os professores das áreas de estudo - de $5^{a}$ a $8^{\mathrm{a}}$ série $/ 6^{\circ}$ ao $9^{\circ}$ ano, gerenciem os grupos. Afinal, vários talentos haviam sido revelados nos encontros pedagógicos.

Definidas as áreas e listados os 'professores articuladores' que teriam uma carga horária de sala de aula reduzida à metade. A premissa era a de que um colega de sala de aula, de trabalho reconhecido, teria melhores condições de mobilizar e articular os demais. Obviamente que as diretrizes seriam discutidas e definidas em acordo com as equipes pedagógicas da Semed que, à altura, já pensavam em estratégias para valorizar o espaço e motivar os professores; a ideia de certificar as horas frequentadas por cada educador no final do ano teve excelente acolhida.

Entretanto, havia técnicos e pequenos grupos de estudos, notadamente aqueles que resistiram às descontinuidades administrativas da Semed, uma incredulidade quanto à funcionalidade das medidas de incentivo: defendiam a obrigatoriedade da participação. Argumentavam que se sentiam desestimulados, já que a maioria dos colegas não frequentava o $\mathrm{PHE}$ e "ganhava do mesmo jeito!"; que se sentiam discriminados nas escolas porque apontados como fiéis seguidores da Secretaria (para não citar palavras desabonadoras ou chulas que ouviam).

Alguns cobravam da autoridade uma posição mais radical: “Descontar o ponto de quem não aparece!” Entretanto, a equipe gestora apostava numa política de incentivos; não se dispunha a entrar em tensão com professores, acreditando que presenças 'obrigatórias' poderiam, no limite, destruir o trabalho de um grupo.
O Programa foi estruturado nos seguintes moldes: grupos de estudo por área (Língua Portuguesa, Matemática, História, Geografia, Ciências Físicas e Biológicas, Artes, Língua Inglesa, Educação Física e Ensino Religioso), e por segmento/modalidade de atuação (Alfabetização e Letramento, Educação de Jovens e Adultos, Educação Especial, Educação Infantil, esse último dividido nas modalidades de Creche e Pré-Escola). Até o final de 2010, mais grupos se constituíram: Coordenadores Pedagógicos, Coordenadores Administrativos, Suportes Pedagógicos e, por fim, o grupo de Funcionários Administrativos - esse por reivindicação dos próprios funcionários reunidos num curso de capacitação ministrado no Cemarh.

Eram estabelecidos dois encontros por mês e ofertados nos três turnos a fim de que o professor possa frequentá-los em horário contrário àquele em que ministra suas aulas. 0 calendário era definido no final do ano anterior e divulgado através de cartazes e folders em todas as escolas da rede. Os temas de estudo, palestras e outras atividades são propostos pelas equipes da Secretaria e pelos professores, através dos seus articuladores. Cabe aos articulares fazer a ponte entre a Semed e os colegas, convidando-os para as reuniões, propondo temas, textos, palestrantes a serem convidados. A Diretoria de Ensino - Densi, através do Departamento de Educação Básica - Deba, responsabilizava-se pela organização, acompanhamento e avaliação do Programa. A direção do Cemarh cuida do espaço, oferecendo as acomodações, equipamentos e demais suportes necessários ao bem-estar dos participantes, anota e realiza levantamentos de frequência e emite certificados.

Naquele ano de 2005, a Secretaria mobilizou-se para a elaboração do Plano Municipal de Educação. Além dos fóruns, (geral e por segmento), o espaço do PHE foi importante na sensibilização dos professores, 
contribuindo para constituição de comissões de trabalho. Infelizmente, essa importante iniciativa foi interrompida por contendas entre a gestão municipal e o sindicato e, embora muitos passos tenham sido dados, o Plano Municipal de Educação de Aracaju ainda está inconcluso após quase oito anos do seu início.

Em 2006, o Cemarh passou por uma reforma significativa, com melhoria das instalações e equipamentos, inclusive com a inserção do Núcleo de Tecnologia Educacional, a fim de capacitar professores e funcionários em informática educativa e tecnologias educacionais. Vários cursos e treinamentos foram ministrados, inclusive para adolescentes estudantes a fim de prepará-los para monitoria nos laboratórios das escolas da rede.

A confecção de um cartão "Credencial do Professor", que seria apresentado para meia-entrada em cinemas e espetáculos, no lugar dos contracheques, foi bem recebida pelos professores, notadamente, entre os frequentadores do programa que tiveram prioridade na sua obtenção.

\section{3 a REESTRUTURAÇÃO DO PHE: PREMIAÇÕES E CONDICIONALIDADES}

Animada com o aumento considerável na frequência dos professores no Programa, a Secretaria resolveu instituir prêmios de participação. No final de 2006, o professor mais frequente de cada grupo ganhou uma viagem de estudos a qualquer lugar do país, com passagens e hospedagem pagas pela Semed, desde que comprovasse sua inscrição em evento educacional, com duração máxima de cinco dias. Foram 15 viagens e vários outros prêmios para os segundos e terceiros lugares.

Desde então, adotou-se o critério da participação no PHE como condição para o professor pleitear custeio da Secretaria para viagens de estudo e outras concessões. A frequência no programa também conta para a Avaliação de Estágio Probatório, embora não se constituísse em critério relevante para a reprovação do novato.

Outra iniciativa em prol do fortalecimento do programa foi o projeto "O Autor vai ao Professor". 0 projeto visava levar obras e autores sergipanos aos professores frequentadores da 'Hora de Estudo'. As obras eram adquiridas pela SEMED que promovia os lançamentos dos livros, com distribuição gratuita e lanche. A saudosa professora Maria Thétis Nunes inaugurou o projeto, lançando seu livro "História Colonial de Sergipe II", ocasião em que se emocionou ao rever ex-alunos de décadas passadas. José lbarê Costa Dantas, Jorge Carvalho do Nascimento, Eva Maria Siqueira, José do Patrocínio Hora, Lílian Rocha e Ana Maria Medina foram alguns dos nomes que estiveram relançando seus livros no Projeto.

Se, por um lado, o programa foi um espaço de divulgação, sensibilização e conquista de adesão dos professores à política pedagógica da Semed, por outro, essa política foi ampliada e enriquecida pela contribuição docente. As 'Semanas Temáticas', onde se abordam assuntos do interesse social sobre os quais a escola não pode estar alheia, trazem profissionais e instituições da sociedade civil, como pesquisadores das universidades sergipanas e de outros estados, Ministério Público, Conselhos Tutelares, Tribunal de Justiça, Embrapa, Petrobrás e Secretarias da Saúde, da Assistência Social, do Meio Ambiente. Desse modo, os temas da violência, água e meio ambiente, qualidade de vida, saúde do estudante, direitos humanos, respeito ao idoso, uso do piercing e tatuagem estiveram na pauta de discussão. 
Projetos sócio-educativos federais desenvolvidos na rede contam com o espaço do PHE, a exemplo de "Vamos Cuidar do Brasil com as Escolas" e "Saúde e Prevenção na Escola". Os programas pedagógicos do Ministério da Educação, tais como Programa de Apoio à Leitura - Praler (Alfabetização nas $1^{\mathrm{a}} \mathrm{s}$ e $2^{\mathrm{a}} \mathrm{s}$ séries) e GESTAR I (Língua Portuguesa nas $3^{\mathrm{a}} \mathrm{s}$ e $4^{\mathrm{a}} \mathrm{s}$ séries), também foram desenvolvidos no PHE.

Para minimizar a defasagem idade-série, a Semed aderiu em 2007 os Programas de Correção de Fluxo SE LIGA e ACELERA do Instituto Ayrton Senna, capitaneados em Sergipe pela Secretaria de Estado da Educação. Mesmo enfrentando a resistência sindical e de parte dos professores, os programas foram desenvolvidos, tendo o tempo do PHE complementado pelo tempo da escola nos planejamentos semanais.

As ‘Quintas de Ampliação’, destinadas à formação continuada dos Educadores Assistentes (profissionais que educam e cuidam das crianças de 0 a 3 anos nas creches) tiveram lugar no PHE. Os encontros aconteciam à noite, com temas como: organização da rotina e dos espaços da creche; cadernos de observação e álbum do bebê; confecção de jogos e brinquedos pedagógicos; saúde infantil, dentre outros. Alguns desses encontros contaram com a presença de pediatras renomados.

O PHE também tem propiciou a visita dos professores com seus alunos a outros espaços da cidade. Visitas a exposições de arte, a praças, igrejas, monumentos e parques da cidade eram custeadas pela Secretaria da Educação, sendo uma das mais importantes as "Caminhadas de Leitura”, onde professores e alunos da Educação de Jovens e Adultos/Alfabetização de Adultos faziam frequentes passeios pela cidade, chegando até a Orla da Atalaia.
O grupo de História e Geografia chegou a produzir textos sobre cultura, economia, política e história de Sergipe que, infelizmente, não foram publicados pelo desinteresse e/ou indisposição da maioria em revisar seus trabalhos. Cursos de linguagem cinematográfica com exibição de filmes nacionais, literatura de cordel, produção de textos e palestras com nomes da literatura sergipana figuram na formação dos professores de Língua Portuguesa.

O grupo de estudo de Educação Física teve sua proposta acatada pela Secretaria que realizou o I Jogos Estudantis da Prefeitura Municipal de Aracaju, num grande e concorrido evento que levantou a autoestima de alunos e principalmente de professores. 0 pessoal de Arte produziu painéis com fotografias de obras e artistas sergipanos. Por sugestão do grupo de Educação Infantil, foram oferecidas oficinas de Contação de Histórias, Confecção de Bonecos, Leitura Dramática e Teatro que teve entre seus participantes professores, funcionários e até mães de alunos.

A maior mobilização que o PHE alcançou ocorreu entre os anos de 2007 e 2008, quando da elaboração do "Conteúdo Programático da Rede Municipal de Ensino". Capitaneado pelo Departamento de Educação Básica - Deba e contando com assessoria de mestres e doutores das duas maiores instituições de ensino superior do estado, a publicação foi assinada por mais de 250 professores da rede, reunidos nos encontros para os estudos e discussões do documento. (Aracaju, 2008). O entusiasmo dos participantes pode ser sentido quando do lançamento da sua publicação em evento que congregou mais da metade dos professores municipais. 


\section{UM BALANÇO DAS AÇÕES DE FORMAÇ̃̃O CONTINUADA ATRAVÉS DO PHE: O DESAFIO DA ADESÃO}

A literatura corrente sobre o tema demonstra que a trajetória da formação continuada na Rede Pública Municipal de Ensino de Aracaju se assemelha a tantas outras do país; vivenciando os mesmos modelos, experimentando inovações, amargando retrocessos e alimentando esperanças.

Rheinheimer (2007) estudou a política de formação contínua da Secretaria Municipal de Florianópolis, entre os anos de 2003 e 2005. Constituída basicamente pela oferta de cursos, seminários e encontros, a autora aponta que $64,8 \%$ dos docentes reivindicam que a formação se dê dentro dos seus horários de trabalho.

Não é o caso da Rede de Ensino de Aracaju, onde os professores conquistaram tempo e espaço. O PHE acontece com cerca de dezesseis encontros anuais, com 64 horas-ano que, acrescidas das horas de estudo na escola, perfazem um total de 128 horas remuneradas num ano letivo. Isto sem contar 15 horas semanais que os professores dispõem para estudar e planejar fora da escola e da Semed.

Desse modo, o PHE é apenas uma parte da formação continuada, visto que os cursos e seminários continuaram acontecendo. Encontros a cada quinze dias não dão conta da necessária regularidade, articulação e sequência de saberes, competências e habilidades próprias a um modelo de formação tipo 'curso' que, invariavelmente, os educadores necessitam para o desenvolvimento de programas e projetos.

Candau (2003, p. 53) refere-se à "perspectiva clássica de formação contínua”. Segundo ela, esse modelo se caracteriza pela oferta de cursos, palestras e seminários sem continuidade e conexões entre si; evidenciando um constante recomeço. É como se os saberes docentes pudessem ser neutralizados e se construísse novos saberes capazes de melhorar a prática pedagógica.

Do ponto de vista da unidade gestora, parece ser um modelo inevitável, ainda que improdutivo. Isto porque ele é reforçado pela própria movimentação interna da rede, com a mobilidade dos mestres entre séries/anos ou modalidades e o ingresso de novos professores que exigem reedições de eventos já realizados. Por outro lado, esses cursos, oferecidos periodicamente a grupos de professores de uma série/ano/ modalidade podem trazer uma nova abordagem de velhos problemas e propiciar o encontro entre os mais experientes com os novos, o que por si só constitui oportunidades de trocas e aproximações produtivas. É o que as instituições promotoras devem estar atentas.

Os autores são unânimes em reconhecer a importância da formação continuada na escola. Entretanto, mesmo constando da política municipal, essa formação quase que não acontece entre nós; isto porque raras são as escolas que promovem encontros de planejamento e estudo e, quando isso ocorre é sempre à custa da carga horária do aluno - invariavelmente, acontecem aos sábados, considerando-se letivo um dia em que não há aulas, mas reuniões de professores e/ou de Conselhos Escolares.

Há problemas estruturais de fundo nessa ausência de formação continuada na escola em todo o país. Salvo raras exceções, a escola brasileira não foi (e ainda não é) concebida arquitetonicamente como ambiente de estudo individual ou coletivo do professor, pois quase todos os prédios contam apenas com uma 'sala de professores' que serve para o descanso 
das trocas de sala de aula ou para o recreio docente. É onde ocorrem os encontros rápidos e fortuitos, nos quais uma conversa (que pode ser uma troca de experiência produtiva) não durará mais de dez minutos sem que o horário de aula do aluno não seja reduzido.

Outro problema é a carga horária contratual do professor brasileiro que não prevê tempo para essa atividade na escola ou na rede; as conhecidas "horas de coordenação' tem sido uma migalha de hora remunerada para que o professor estude, planeje e corrija em casa. Temos ainda as condições salariais que quase obrigam o professor a procurar um segundo emprego. Desse modo, para uma parcela considerável do professorado, o tempo de aula é escorchante; são oito horas diariamente em classe (nos dois empregos), dos quais acumula uma infinidade de tarefas de planejamento, leitura, correções.

Quanto ao PHE, mesmo com a política de estímulo à frequência e as iniciativas que tentam incluir o professor como sujeito da sua própria formação, a participação do conjunto do magistério ainda é muito diminuta. Há áreas de estudo que contam com uma participação mais significativa (chega a reunir cerca de 20 professores) e outras que não consegue juntar mais de três docentes. Também ocorrem enormes diferenças no número de participantes de um mesmo grupo, dependendo do horário dos encontros. E por que isso ocorre? Por que não se consegue sensibilizar e mobilizar todos, ou pelo menos a maioria dos professores?

Quanto à formação contínua na escola, Fusari (1998) aponta que é importante que "diretores e coordenadores pedagógicos liderem e promovam espaços e oportunidades de formação reflexiva sobre a prática da sala de aula”. As horas de estudo para diretores e coordenadores pedagógicos são relativamente recentes em nossa rede, de modo que ainda são poucas as lideranças que promovem essas oportunidades; muitas sequer comunicam e orientam o docente recém-chegado na escola sobre a importância e mesmo a 'obrigação' de frequentar o PHE. Disso decorre que, passadas mais de duas décadas da institucionalização legal das horas de estudo, boa parte dos protagonistas da luta não as absorveu como uma conquista, uma oportunidade de melhorar o trabalho individual e coletivo da escola. Por outro lado, a Secretaria de Educação não tem empreendido ações que desafiem a escola a pensar seu pedagógico, nem tem cobrado suficientemente a elaboração coletiva de respostas referentes aspectos sobre os quais o conjunto dos professores reivindica autonomia.

As mudanças de 'foco de formação contínua' das gestões que se sucederam na Secretaria contribuem para o quadro, já que o PHE não vem sendo mantido com a regularidade e intensidade necessárias; como vimos, uma gestão inaugurou o PHE, a seguinte mudou o foco para o estímulo à produção acadêmica (Revista Hora de Estudo), outra investiu nos encontros pedagógicos priorizando a elaboração e execução de projetos na escola. Essa descontinuidade não permite o desenvolvimento de um 'habitus' na acepção de Bourdieu.

Uma questão que se coloca para a última gestão, que recuperou o programa de modo sistematizado, é a capacitação dos formadores (articuladores). Salvo algumas iniciativas pontuais, não há entre nós parcerias com instituições formadoras para a capacitação continuada do professor, como ocorre em outros sistemas de ensino. 0 saber e a autoridade intelectual, a liderança e a mobilização, a mediação e solução de conflitos são capacidades construídas; portanto, o investimento na formação dos seus próprios técnicos e dos professores articuladores é uma alternativa valiosa à ampliação e consolidação do PHE. Como diz Perrenould (1998, p. 207), é necessária a “criação de um corpo de formadores e de serviços que garantam a oferta regular de formação contínua em temas que não estejam distantes demais das práticas profissionais, dos programas, dos modos de funcionamentos específicos da escola".

Nesse sentido, o Programa Nacional de Inclusão de Jovens - ProJovem Urbano desenvolvido no mu- 
nicípio desde 2006 é um modelo a ser seguido. Mediante convênios com agências formadoras, o ProJovem investe na formação inicial e continuada dos formadores, inclusive com momentos de encontro entre educadores (professores de sala de aula) e formadores (professores que orientam e acompanham estudos e planejamentos semanais). Os professores desse programa são contratados temporariamente e assumem uma carga horária obrigatória de estudo e planejamento; o que não ocorre com os professores efetivos da rede. (BRASIL, 2008)

Um alento é que não estamos sós quanto a pouca adesão dos professores a programas de formação continuada. Refletindo sobre o tema, Perrenoud (1998) reconhece que esse é um fenômeno mundial e que "em todo lugar" metade dos professores praticamente não participa e somente um quarto se engaja efetivamente.

Quanto à alternativa da obrigatoriedade, o estudioso francês alega que elas veem sendo progressivamente abandonadas; que não se pode apostar na profissionalização e convocar os professores através de medidas autoritárias. Diz ainda que não se pode desconsiderar as diferenças entre os professores, uma vez que as "reciclagens-padrão" podem ser "por demais elementares para alguns e claramente insuficientes para outros". (PERRENOUD, 1998, p. 207)

Outros pesquisadores, entretanto, sugerem que essa questão deva ser acordada com os próprios professores, a exemplo de Fusari (1998, p. 47), para quem uma formação contínua que contemple projetos desenvolvidos pela secretaria com as escolas precisa analisar com os professores o que é obrigatório e o que é facultativo, pois, "a participação em algumas atividades de formação em serviço pode ser obrigatória, desde que articulada ao desenvolvimento do projeto pedagógico das escolas".

Rheinheimer posiciona-se a partir dos próprios dados da pesquisa, onde os professores não querem a formação continuada como sobrecarga adicional de trabalho, portanto, desde que faça parte da carga contratual, a obrigatoriedade estaria legitimada.

Outro aspecto importante nos estudos sobre formação continuada é a difícil compatibilização entre as necessidades manifestadas pelos educadores e a política educacional definida pelos sistemas. Sobre isso, a autora nota que "há necessidade de parceria entre as escolas e a Secretaria de Educação que garanta a participação dos professores na tomada de decisões acerca da sua própria formação" (RHEINHEMER, 2007, p. 13). Já Perrenoud pondera que “o respeito à liberdade de escolha de cada um deixa 0 sistema educativo bastante desprovido da articulação necessária entre política educacional e formação contínua”. (PERRENOUD, 1998, p. 207)

Este tem sido um problema dos governos democráticos, eleitos com um programa educacional legitimado pela maioria da população, mas cujo sucesso depende da parceria com a corporação docente; um processo cheio de percalços. Por ocasião das negociações salariais, notadamente em períodos de contendas mais acirradas, o PHE sofria consequências; estimuladas pelas lideranças sindicais, parcelas do professorado se ausentavam dos encontros. Em tempos de paz, raros participantes manifestaram discordância com as orientações e diretrizes da política educacional e pedagógica da SEMED dentro do PHE. Parece que aqueles que discordam não participam e os que não participam se servem do argumento da discordância. É uma hipótese!

Essas e outras questões sugerem que o sistema precisa implantar um processo de avaliação da sua política de formação continuada que investigue seus reflexos/resultados na sala de aula, na aprendizagem dos alunos, ouvindo também os infrequentes. A implantação de avaliações próprias em larga escala, discutidas com o magistério e que considerem também os fatores intra e extraescolares, pode ser um poderoso instrumento de planejamento e redefinições. 
Avaliações das políticas de formação continuada ainda são procedimentos incipientes em nosso país, como aponta Gatti (2008, p. 67). A autora assevera que no Brasil ainda não dispomos de avaliações posteriores aos programas públicos implementados, a fim de saber se as novas práticas se consolidaram no chão das escolas. Ela comenta uma pesquisa de Géglio (2006) que consultou professores saídos de processos de formação continuada, sobre seus efeitos na prática de sala de aula; todos evidenciaram que, em maior ou menor medida, a participação em atividades de formação contínua resultou em mudanças nas suas práticas de sala de aula. Assim, é importante ouvir os professores, principalmente os resistentes, os infrequentes, pois, como diz Imbernón (2002, p. 40), uma proposta de formação continuada deve levar em conta "o meio, o grupo, a instituição, a comunidade, as bases implícitas, as decisões e as atitudes do professorado".

Sempre estive convencida de que a formação contínua é um contributo imprescindível na melhoria da qualidade do ensino, embora não se constitua numa política redentora, capaz de resolver todas as dificuldades do processo de 'aprendizagem-ensino-aprendizagem'. Todavia, até cotejar os estudos sobre o tema para escrever este artigo, advogava que, no Brasil, uma política de formação continuada somente teria relativo sucesso quando se estabelecesse para todo o magistério público a jornada única acompanhada de um salário digno. É curioso que grande parte dos nossos colegas europeus já usufrui desse privilégio e, mesmo assim, conforme apontam alguns dos autores consultados, a maioria não participa das atividades de formação contínua.

Claro que muitos outros fatores concorrem para que uma parcela significativa do magistério básico não persiga a máxima socrática da eterna busca do conhecimento, nem se esforce para fazer brotar da ignorância e incertezas dos seus alunos o conhecimento revelador e prazeroso! Terei que retomar em outra oportunidade esses estudos para buscar respostas; sempre provisórias e provocadoras de mais perguntas.

Por ora, fico com a ponderação de Fusari: “A formação contínua não pode ser uma atribuição de responsabilidade exclusiva do Estado, pois cada professor é responsável por seu desenvolvimento pessoal e profissional, cabendo-lhe a direção, percepção e decisão do caminho que vai percorrer".

\section{REFERÊNCIAS}

ALMEIDA, M. I. $O$ trabalho dos educadores. In: Silva, A. M. M. \& Aguiar, M. A. S. (orgs.) Retrato da escola no

Brasil. Brasília: CNTE, 2004, p.105-118.

ARACAJU. SECRETARIA MUNICIPAL DE EDUCAÇÃO. Relatórios Anuais do Centro Municipal de Aperfeiçoamento de Recursos Humanos - CEMARH. 2005 a 2010.

ARACAJU. SECRETARIA MUNICIPAL DA EDUCAÇÃO. COSTA, Patrícia Rosalba S. Moura (org.). Programa de Conteúdos do Ensino Fundamental e EJA da Rede Municipal de Ensino de Aracaju. Aracaju, 2008.

ARACAJU. SECRETARIA MUNICIPAL DE EDUCAÇÃO. Memorial de Gestão: 2005 a 2008. PMA/SEMED, 2009. 
BRASIL. MEC/SEB. Rede Nacional de Formação Continuada de Professores de Educação Básica: orientações gerais, 2005.

BRASIL. MEC/FNDE. Resolução n. 22, de 26 de Maio de 2008.

CANDAU, Vera Maria. Formação continuada de professores: tendências atuais. In: CANDAU (org.). Magistério: construção cotidiana. 6ª Ed. Petrópolis: Vozes, 2008.

FUSARI, José Cerchi. Formação contínua de educadores: um estudo de representações de coordenadores pedagógicos da Secretaria Municipal de Educação de São Paulo (SMESP). 1998. Tese (Doutorado em Educação) - Faculdade de Educação da USP - FEUSP, São Paulo, 1998.

GATTI, Bernadete A. Análise das Políticas Públicas para Formação Continuada no Brasil, na última Década. In: Revista Brasileira de Educação. v. 13. n. 37. jan/abr. 2008.

GRAÇA, Tereza Cristina C. da, SOUZA, Josefa Eliana e SANTOS, Betisabel Vilar de J. A Cartilha do Barnabé: a educação pública municipal no governo de Conrado de Araújo (1959-1963). Aracaju: PMA/SEMED/Sercore, 1996.

IMBERNÓN, F. Formação docente e profissional: formar-se para a mudança e a incerteza. $3^{a}$ ed. São Paulo: Cortez, 2002.

PERRENOUD, Philippe. Formação Continua e Obrigatoriedade de Competências na Profissão de Professor. Genebra: FPCE/Universidade de Genebra, 1998. (tradução de Luciano Lopreto)

RHEINHEIMER, Adriana de Freitas. Política de Formação Contínua de Professores: a descontinuidade das ações e as possíveis contribuições. 2007. Disponível em: http://www.anped.org.br/reunioes/30ra/trabalhos/ GT08-2966--Int.pdf Acesso: 10 jul. 2012.

TORRES, Rosa Maria. Tendências da formação docente nos anos 90. In: WARDE, Mirian Jorge (org.). Novas políticas educacionais: críticas e perspectivas. SP: Programa de Estudos Pós-Graduados em Educação: História e Filosofia da Educação da PUC/SP, 1998. p. 173-191.

Recebido em: 5 de agosto de 2013 Avaliado em: 15 de agosto de 2013 Aceito em: 23 de agosto de 2013
1 Professora da Universidade Tiradentes, doutoranda do Dinter - Doutorado Interinstitucional da PUCRS-UNIT. Ex-secretária da Educação do Município de Aracaju, Integrante do Conselho Estadual de Educação. Email: tccgraca@yahoo.com.br 